\title{
A Handbook of Statistical Analyses Using R
}

Brian S. Everitt and Torsten Hothorn 


\section{Multidimensional Scaling: British Water Voles and Voting in US Congress}

\subsection{Introduction}

\subsection{Multidimensional Scaling}

\subsection{Analysis Using R}

We can apply classical scaling to the distance matrix for populations of water voles using the $\mathrm{R}$ function cmdscale. The following code finds the classical scaling solution and computes the two criteria for assessing the required number of dimensions as described above.

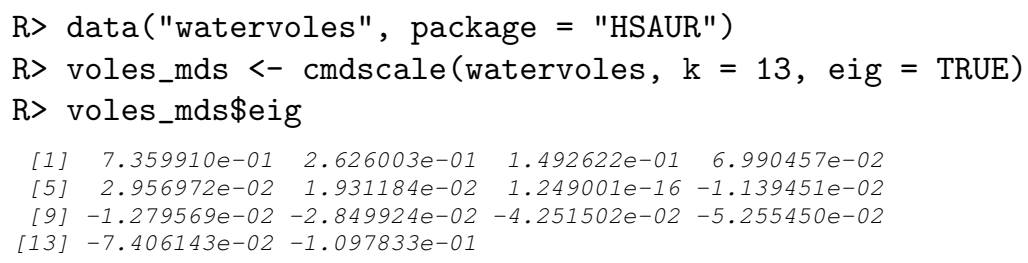

Note that some of the eigenvalues are negative. The criterion $P_{2}$ can be computed by

$R>\operatorname{sum}\left(a b s\left(v o l e s \_m d s \$ e i g[1: 2]\right)\right) / \operatorname{sum}(\operatorname{abs}($ voles_mds\$eig))

[1] 0.6248056

and the criterion suggested by Mardia et al. (1979) is

$R>\operatorname{sum}(($ voles_mds\$eig[1:2] )`2)/sum ((voles_mds\$eig)`2)

[1] 0.9220468

The two criteria for judging number of dimensions differ considerably, but both values are reasonably large, suggesting that the original distances between the water vole populations can be represented adequately in two dimensions. The two-dimensional solution can be plotted by extracting the coordinates from the points element of the voles_mds object; the plot is shown in Figure 14.1.

We shall now apply non-metric scaling to the voting behaviour shown in Table ??. Non-metric scaling is available with function isoMDS from package MASS (Venables and Ripley, 2002):

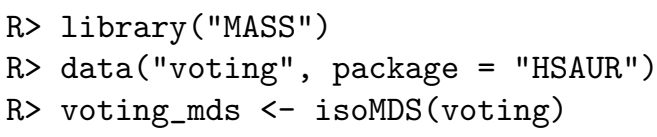



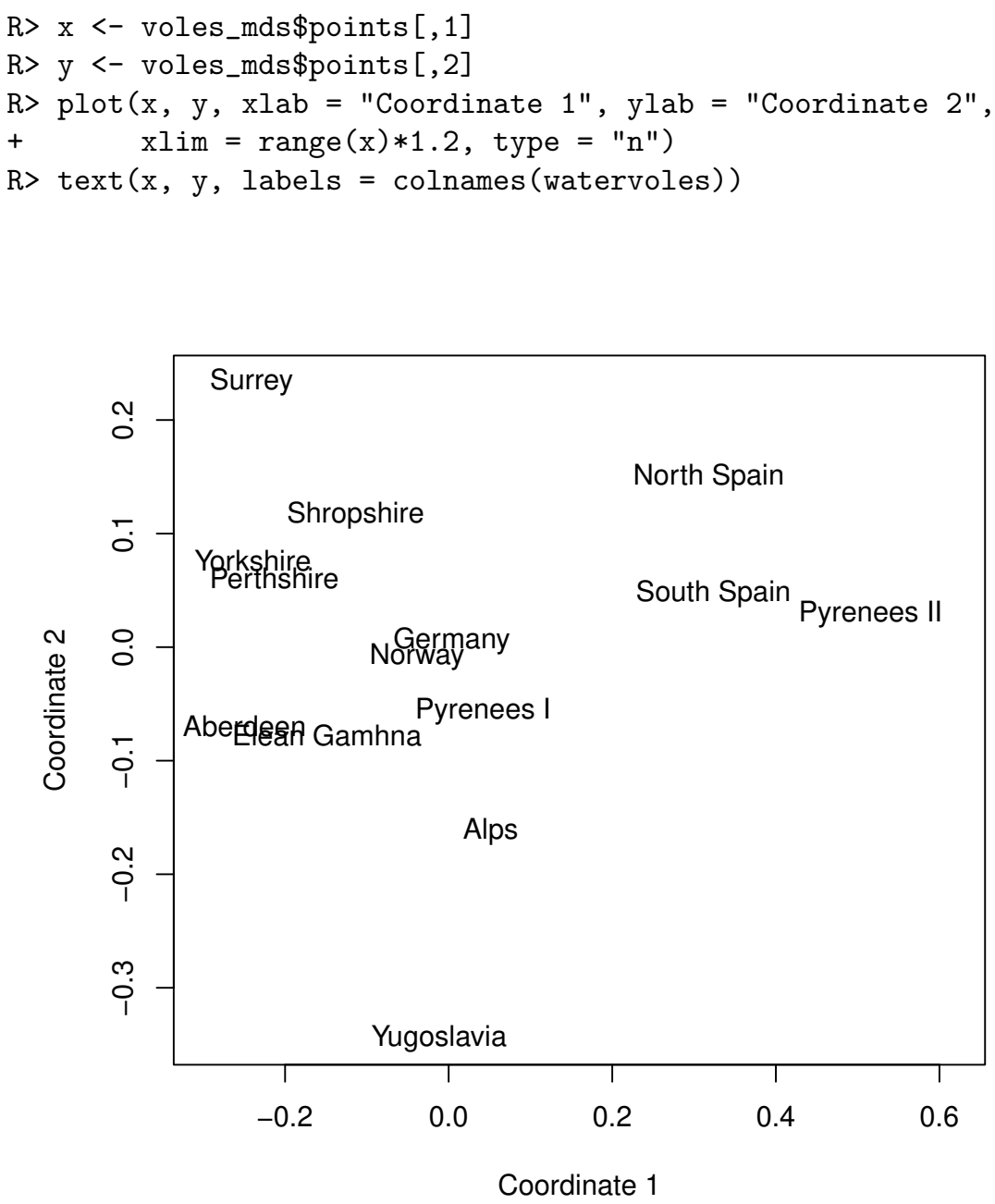

Figure 14.1 Two-dimensional solution from classical multidimensional scaling of distance matrix for water vole populations.

and we again depict the two-dimensional solution (Figure 14.3). The Figure suggests that voting behaviour is essentially along party lines, although there is more variation among Republicans. The voting behaviour of one of the Republicans (Rinaldo) seems to be closer to his democratic collegues rather than to the voting behaviour of other Republicans. 

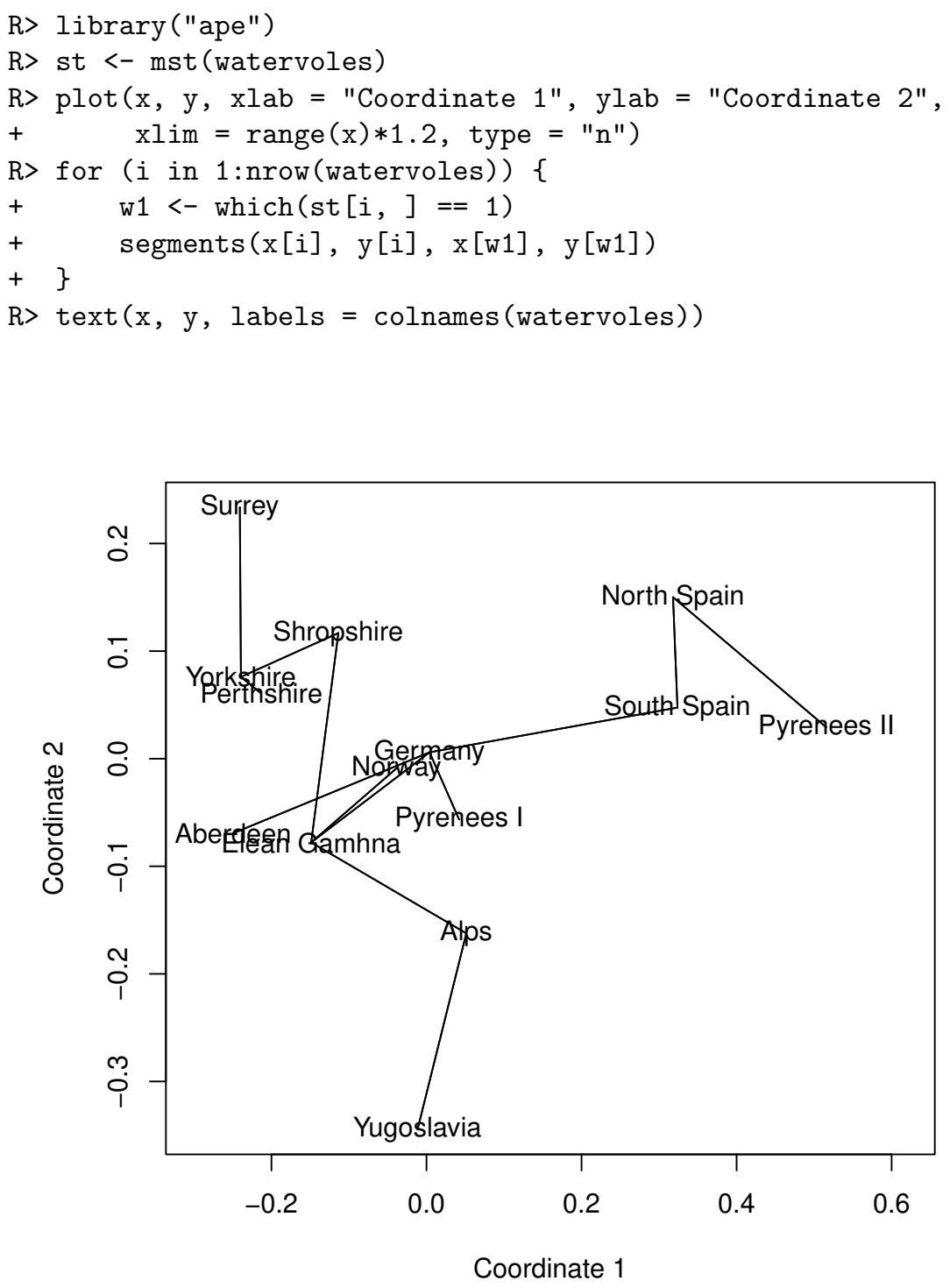

Figure 14.2 Minimum spanning tree for the watervoles data. 
$\mathrm{R}>\mathrm{x}<-$ voting_mds\$points $[, 1]$

$\mathrm{R}>\mathrm{y}<-$ voting_mds\$points $[, 2]$

$\mathrm{R}>\mathrm{plot}(\mathrm{x}, \mathrm{y}, \mathrm{xlab}=$ "Coordinate $1 ", \mathrm{ylab}=$ "Coordinate 2",

$+\quad \mathrm{xlim}=\operatorname{range}(\operatorname{voting}$ mds $\$$ points $[, 1]) * 1.2$, type $=" n ")$

$\mathrm{R}>\operatorname{text}(\mathrm{x}, \mathrm{y}, \mathrm{labels}=\operatorname{colnames}($ voting $))$

R> voting_sh <- Shepard (voting[lower.tri(voting)],

$+\quad$ voting_mds\$points)

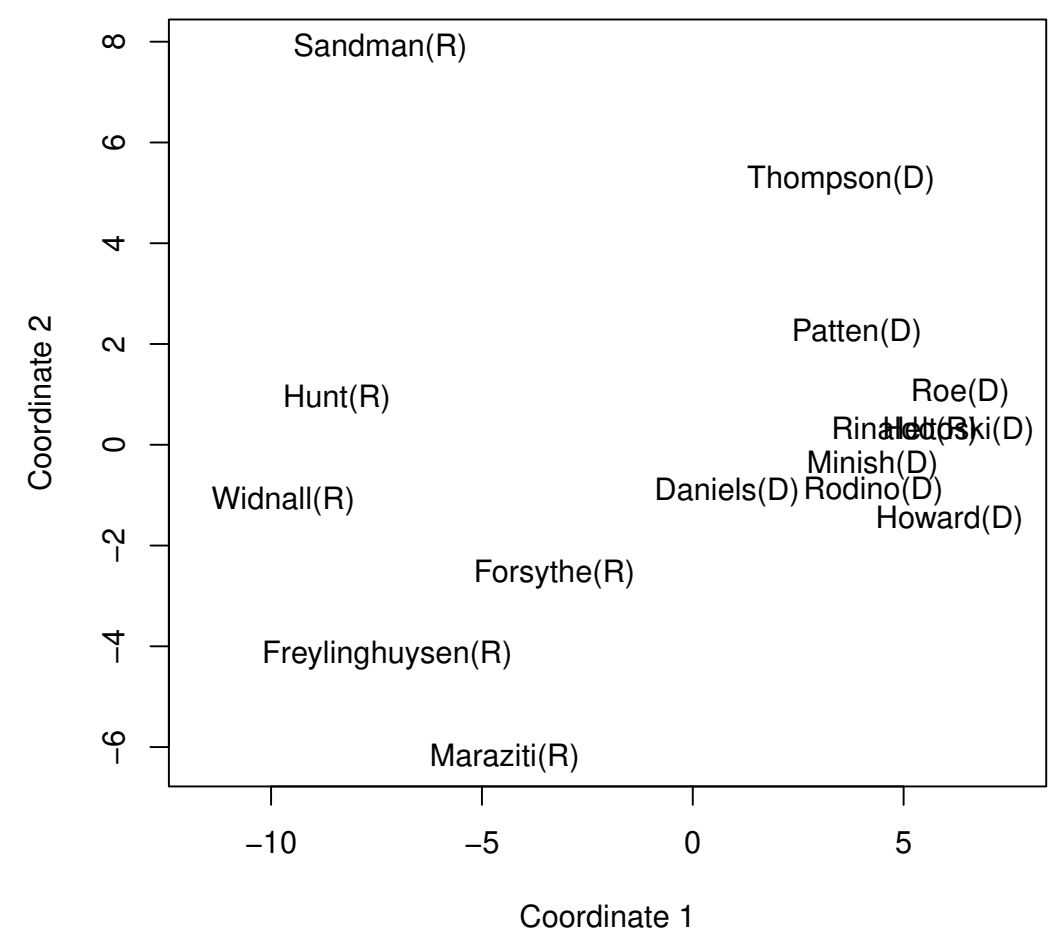

Figure 14.3 Two-dimensional solution from non-metric multidimensional scaling of distance matrix for voting matrix. 
R> plot(voting_sh, pch = ".", xlab = "Dissimilarity",

$+\quad \mathrm{ylab}=$ "Distance", $\mathrm{xlim}=$ range $($ voting_sh $\$ \mathrm{x})$,

$+\quad \mathrm{ylim}=$ range (voting_sh $\$ \mathrm{x})$ )

R> lines (voting_sh $\$ \mathrm{x}$, voting_sh $\$ y f$, type = "S")

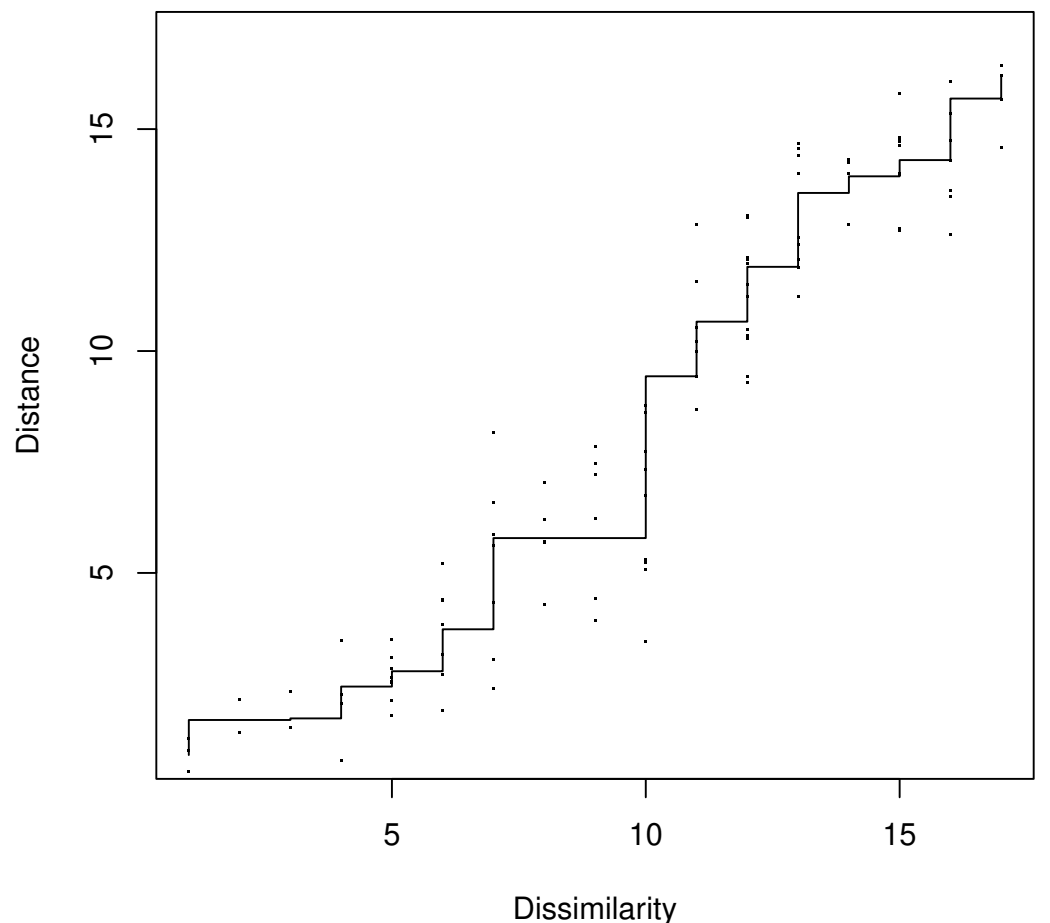

Figure 14.4 The Shepard diagram for the voting data shows some discrepancies between the original dissimilarities and the multidimensional scaling solution. 


\section{Bibliography}

Mardia, K. V., Kent, J. T., and Bibby, J. M. (1979), Multivariate Analysis, London, UK: Academic Press.

Venables, W. N. and Ripley, B. D. (2002), Modern Applied Statistics with $S$, Springer, 4th edition, URL http://www.stats.ox.ac.uk/pub/MASS4/, ISBN 0-387-95457-0. 